\title{
Analysis of the Capital Asset Pricing Model: Application to General Electric Performance
}

\author{
Issam Tlemsani*, Alanoud Alkhaldi, Batool Aljeshi, Israa Alluwaimi, Jawaher Alrayes \\ The Center of International Business Policy, London, United Kingdom \\ Email: ^i.tlemsani@tcib.org.uk, Alanoudnalkhaldi@hotmail.com,Batool.m.aljishi@gmail.com, esraaib1@gmail.com, \\ Jwaher79alrayes@gmail.com
}

How to cite this paper: Tlemsani, I., Alkhaldi, A., Aljeshi, B., Alluwaimi, I., \& Alrayes, J. (2020). Analysis of the Capital Asset Pricing Model: Application to General Electric Performance. Theoretical Economics Letters, 10, 1103-1112.

https://doi.org/10.4236/tel.2020.105065

Received: September 6, 2020

Accepted: October 23, 2020

Published: October 26, 2020

Copyright $\odot 2020$ by author(s) and Scientific Research Publishing Inc. This work is licensed under the Creative Commons Attribution International License (CC BY 4.0).

http://creativecommons.org/licenses/by/4.0/

\begin{abstract}
In the world of investment, the essential question is, to what degree does the risk of a security influence its expected return? The Capital Asset Pricing Model (CAPM) helps in answering this question. CAPM showed that the risk which can be spread away when seized together with other investments in a particular portfolio should not affect asset price. The adequacy of the CAPM theory as a measurement tool of the relationship between a security's beta and the expected return of a security is now seriously challenged as it has a set of assumptions that are mostly criticized by their absence in reality. This research re-examines these assumptions (markets are ideal, all investors are averse to risk, markets are highly efficient, Beta coefficient is the only measure of risk and markets are in equilibrium) by applying them to measure the performance of General Electric between March 2017 and March 2020. The methodology adopted in this study is quantitative approach. The main finding of this research indicates that the risk-free rate decreased, the risk increased and the expected return moved up and down in each year. Therefore, the failure of the CAPM in empirical tests implies that most applications of the model are invalid.
\end{abstract}

\section{Keywords}

CAPM, SML, CML, Beta, SD, Alpha, Return

\section{Introduction}

Markowitz's $(1952,1959,1999)$ CAPM theory is based on a reflection of the relationship between risk and return, by expanding efficient investment portfolios in the market in general and evaluating securities in particular. CAPM has a set of assumptions that are mostly criticized by their absence in reality (Ball, 1978; 
Banz, 1981; Basu, 1983; Cheng \& Graver, 1980; Gibbons, 1980; Marsh, 1980; Reinganum, 1981). Some of them are: perfect market with no transaction or taxation costs, investors are rational and risk-averse, unlimited borrowing and lending at a constant risk free rate (Kenton, 2019); therefore, can CAPM which was built based on these assumptions explain the behaviour and the values of securities in the financial market (Tlemsani \& Nuaimi, 2018)?

This research investigates the performance of General Electric (GE) between 2017 and 2020. The CAPM's assumptions would be tested and applied to validate if they are relevant to reflect on GE's market performance. CAPM's theory has many assumptions that have been criticized; therefore, the importance of this study cannot be ignored; the scope of this research is to discuss these assumptions and compare them with GE's performance between 2017 and 2020.

The main objectives of this paper are to test CAPM's assumptions if they are realistic or not by observing GE's financial performance from 2017 to 2020, and furthermore, to insert the GE's three years average of return into the Security Market Line (SML) and Capital Market Line (CML). The research questions are: Are CAPM's assumptions valid and able to explain the values of GE's securities in the financial market? And what are the reasons for the falling of GE's performance from 2017 to 2020 ?

\section{Literature Review}

This part will be debating the CAPM's assumptions and will cover a brief information about General Electric dilemma during 2017 and 2020. Markowitz (1952) gave details that because economic impacts on risks among assets were correlated to a certain degree, the investors should be able to bring to an end more or less risks by diversifying their portfolio, which means the benefits of diversification depend on correlation. Markowitz (1952: p. 85) wrote: "This presumption, that the law of large numbers applies to a portfolio of securities cannot be accepted. The returns from securities are too intercorrelated. Diversification cannot eliminate all variance."

Black et al. (1972) CAPM empirical studies demonstrate a negative correlation between low Beta stocks and high returns than the CAPM would expect. Harindra (2012), Baker et al. (2010) and Blitz et al. (2019) confirmed that the CAPM facts is in itself rational (which hold back the efficient-market hypothesis but then again marks CAPM incorrect), or it is irrational (which hold back CAPM, but then again marks the EMH incorrect-undoubtedly, this option makes volatility arbitrage a tactic for consistently thrashing the market).

CAPM measures the relationship between beta and the expected return of investing in securities, in which, the expected return of an investment equals the risk-free return plus the market risk premium. CAPM was developed by Sharpe (1964), Treynor (1962), Lintner (1965a, 1965b) and Mossin (1966) and is calculated according to the following formula: 


$$
E(R)=R_{f}+\beta\left(R_{m}-R_{f}\right)
$$

where:

$$
\begin{aligned}
& E(R)=\text { the expected return of a security } \\
& R_{f}=\text { the risk-free rate } \\
& \beta=\text { the risk of the security } \\
& \left(R_{m}-R_{f}\right)=\text { represents the market premium }
\end{aligned}
$$

Fama and French (2004) in their 2004 review, argued that "the failure of the CAPM in empirical tests implies that most applications of the model are invalid". According to Blitz et al. (2014), there are three assumptions to explain the volatility effect that can be linked to CAPM in their book in which they gave specific explanation on leverage, regulatory and short selling constraints.

Bernnan (1971) and Black (1972) proved that the leverage constraints may be the cause of lowering of the security market line slope. As a result, the risk of the stock will be low, causing a high expected return, and this is the opposite of what is predicted by the CAPM model. Sharpe (1964) suggested an increase in the allocation of the stocks that have low risks, for example, investing $80 \%$ in stocks that have a low risk and $20 \%$ on bonds. High risk stocks are usually over-priced because their owners are biased; however, the model shows that a high-risk asset is more inclined to theoretical overpricing than low risk asset. CAPM's assumptions indicated that the investors are risk averse which means investors potentially choose a high-risk asset.

Blitz et al. (2014) stated that some investors avoid the risky assets or stocks and they ignore the median return, which means the investors want to increase the objective function:

$$
(\boldsymbol{E}(\boldsymbol{R P}), \sigma 2(\boldsymbol{R P}))=\boldsymbol{E}(\boldsymbol{R P})-\mathrm{A} / \mathbf{2} \cdot \sigma 2(\boldsymbol{R P})
$$

Moreover, they stated that assumptions are related to behavioral biases towards the market, for example, behavioral bias is overconfidence that the investors see themselves better than the average investors.

\section{Security Market Line (SML) and Capital Market Line (CML)}

According to Lee \& Su (2014), security market line is the relationship between the expected return and the security risk Beta. Also, the risk is divided into systematic and unsystematic risk. Systematic risk means that the market cannot be eliminated and is also known as undiversifiable risk. However, unsystematic risk means that the risk is related to a specific company or industry and is also known as unique risk. Therefore, the investor will choose a specific market portfolio and the risk-free to manage the risk.

CML shows the relationship between the expected return and the standard deviation (risk) and describes how investors react. CAPM shows the CML in a form of how investors should evaluate the risk return for a specific portfolio. Furthermore, SML describes the tradeoff between the risk and expected return as a straight line intersect with the vertical axis at the risk-free rate. 
The main difference between SML and CML is that they measure risk differently, SML measure the risk as beta that calculate the systematic risk, while CML measure the risk as standard deviation that calculate the total systematic and the unsystematic risks.

General Electric is an international power corporation that produces renewable energy, oil and gas, aviation, healthcare, transportation, and lighting products and services. It operates in 180 countries worldwide, serving $33 \%$ of the world's power, preparing $90 \%$ of energy transmission utilities internationally, and its software administers over $40 \%$ of power around the world. GE has more than $\$ 50$ billion in ECA financing capacity, more than $\$ 15$ billion renewable investing experience and more than $\$ 40$ billion of capital investment experience. GE historically is well-known for performing well in the stock market and being highly reliable performing company for example; on Sept $30^{\text {th }}, 2020$ GE's stock price was $\$ 6.23$, the all-time high was $\$ 60.00$ on Aug $28^{\text {th }}$, 2000, the 52-week high stock price is $\$ 13.26$, which is $112.8 \%$ above the current share price and the 52 -week low stock price is $\$ 5.48$, which is $12 \%$ below the current share price, the average GE stock price for the last 52 weeks is $\$ 8.58$. However, between 2017 and 2020, GE experienced many losses that created negative performance.

In 2017, the company laid off thousands of workers which led to huge financial losses specifically in its consolidated revenue that decreased by almost $\$ 1.6$ billion, and its continuing earnings that dropped by $\$ 15$ billion (General Electric Company Financial Reports, 2017); and fall in its stock prices by 3.5\% (Hansen, 2020). In 2018, Dow Jones Industrial Average market index announced that GE would be removed from the index due to their negative performance as its stock prices continues to fall in comparison with the 30 companies performing in the same index. Therefore, the company stock prices dropped by $1.5 \%$ after the announcement (Owens, 2018).

As of the year 2019, the company had fraud allegations of misleading its investors in the financial statements by $\$ 38$ billion. This huge claim affected the company's performance and reputation even more, where its stock prices dropped by almost $11 \%$ which was their greatest drop since the financial crisis in 2008 (Siegel, 2019). GE rejected these meritless allegations. By the beginning of 2020, GE laid off approximately $10 \%$ of its workers which led again to a big fall in its stock prices.

\section{Research Methodology}

The methodology adopted in this study is quantitative approach. The data were gathered from different online resources such as (statista, market watch, investing and macrotrends) which include GE stock prices from March 2017 to March 2020, U.S treasury bills rate (5 years), and S\&P 500 stock prices. In this research, the monthly risk free return, yearly average, market and GE's returns were calculated and employed in determining beta average during each year and for the three years, which were estimated by creating a regression model for each time 
period. Furthermore, the monthly, yearly and the expected return in each year were calculated using the CAPM formula and the three years' average were plotted in the SML and CML.

\section{Data Analysis and Evaluation}

The CAPM had many assumptions that were tested using the GE performance between March 2017 and March 2020 and the following were indicated. The theory assumes that investors could lend and borrow unlimited amount of stocks at the same risk-free rate; however, the risk free rate of the 5 years U.S treasury bills were not stable at all, which can be shown from Figure 1 as it fluctuated in response to the changes in the economy from 16\% in March 2017 to $11 \%$ in March 2020, and it went up and down on a yearly basis, increasing from $16.9 \%$ in the $1^{\text {st }}$ year to $22.6 \%$ in the $2^{\text {nd }}$ year and then decreasing in the $3^{\text {rd }}$ year to reach $14.2 \%$ which proves that risk-free rate carries a little amount of risk in holding them.

Another issue with the empirical testing of the CAPM is that it is based entirely on historical data to reflect the market which is unrealistic as the GE beta during the three years was 0.32 in the $1^{\text {st }}$ year, 1.02 in the $2^{\text {nd }}$ year and 1.99 in the $3^{\text {rd }}$ year. Therefore, if an investor decides to invest in GE and only looked at the beta during the $1^{\text {st }}$ year, it would be assumed that the company stock would be less volatility than the market as the beta during the $1^{\text {st }}$ was 0.32 ; however, GE had gone through a lot during this particular year which affected the financial performance of the GE that beta did not take into consideration as it was unsystematic risk or specific risk that affected GE itself.

DJL index removed GE which led to a fall in their stock prices as can be seen by observing the actual returns of GE that continued to drop through the $1^{\text {st }}$ year when the average actual return was $-6.19 \%$.

In general, investors assume that they would be compensated for holding risky stocks, but GE had an average actual return of $-3.35 \%$ and average beta of 1.4 (Table 1, Table 2 and Table 3) which shows that beta cannot be projected

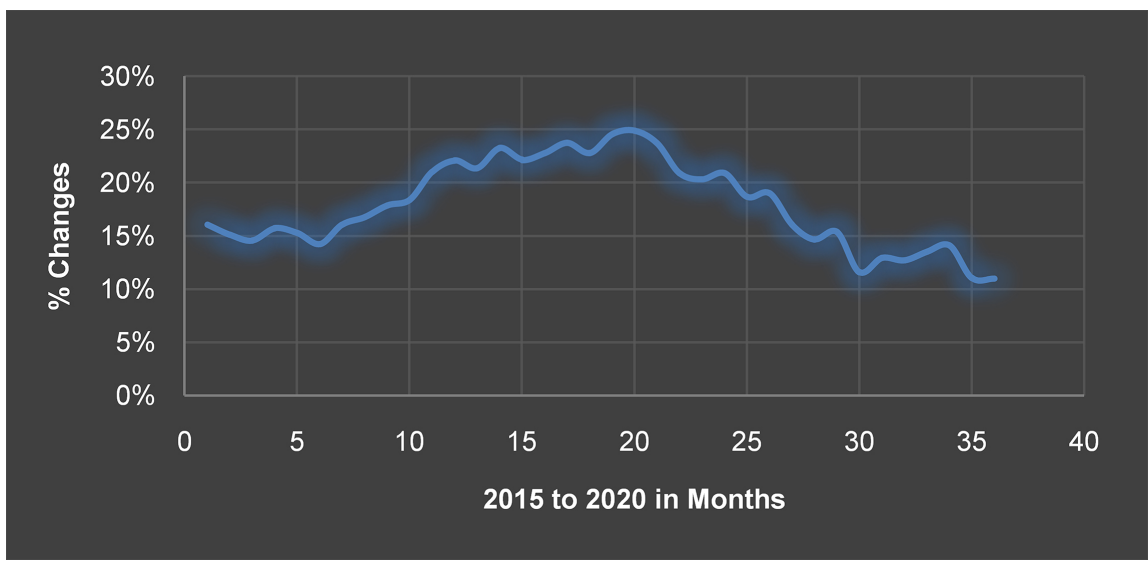

Figure 1. 5 years U.S treasury bills risk-free rate of 36 months. 
accurately as it is historically based. The relationship between the expected return and systematic risk $(\beta)$ can be expressed graphically through the security market line (SML) which is shown in Figure 2; as the average three years expected return is plotted above the SML line, it is considered as undervalued, which means that the stock is selling under its intrinsic value. However, this does not mean that the stock is performing well because even though the stock is priced below its actual value, it did not generate positive alpha.

Table 2 shows that the yearly alpha and the average years were negative, and the consistent underperformance cannot be a promising sign for GE's stock. Figure 3 shows the relationship between the expect return and total risk $(\sigma)$, it was obtained by calculating the standard deviation in which GE had higher SD $(\sigma)$ than the market which means that it is very risky to invest in their stocks as the returns are more spread out.

Let us consider these conclusions and correlate them to the assumption that investors have homogenous expectation, which means that most investors would avoid investing in GE's stock as GE's beta and standard deviation are higher than the market (Table 3 ). This is achieved in a perfect unrealistic market; however, some individuals still invest in GE with hopes of higher return.

Table 1. GE's yearly CAPM formula and performance.

\begin{tabular}{ccccc}
\hline Time & Risk-free rate & Beta & Market premium & Expected return \\
$Y 1$ & $16.9 \%$ & 0.32 & $75.8 \%$ & 0.41 \\
$Y 2$ & $22.6 \%$ & 1.02 & $36.3 \%$ & 0.60 \\
$Y 3$ & $14.2 \%$ & 1.99 & $-91.1 \%$ & -1.67 \\
Yearly average & $17.9 \%$ & 1.34 & $7 \%$ & 0.28 \\
\hline
\end{tabular}

Table 2. GE's Alpha and stock performance.

\begin{tabular}{cccc}
\hline Expected Return & Actual Return & Alpha & Performance \\
\hline 0.41 & -6.19 & -6.60 & Negative \\
0.60 & -2.00 & -2.56 & Negative \\
-1.67 & -1.89 & -0.21 & Negative \\
0.28 & -3.35 & -3.63 & Negative \\
\hline
\end{tabular}

Table 3. GE's three years beta, standard deviation.

\begin{tabular}{ccc}
\hline & $S \& P 500$ & $G E$ \\
\hline $\operatorname{Beta}(\beta)$ & 1 & 1.40 \\
$S D(\sigma)$ & 4.5 & 11.76 \\
\hline
\end{tabular}




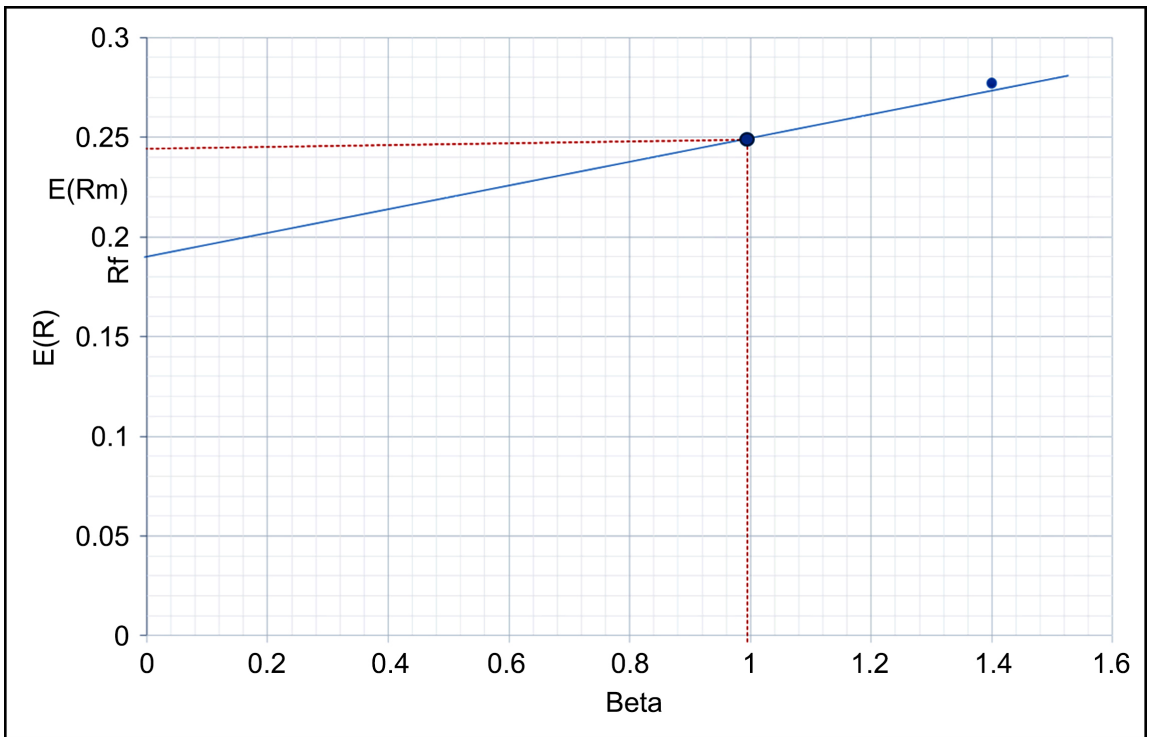

Figure 2. Security Market Line (SML); Three years average.

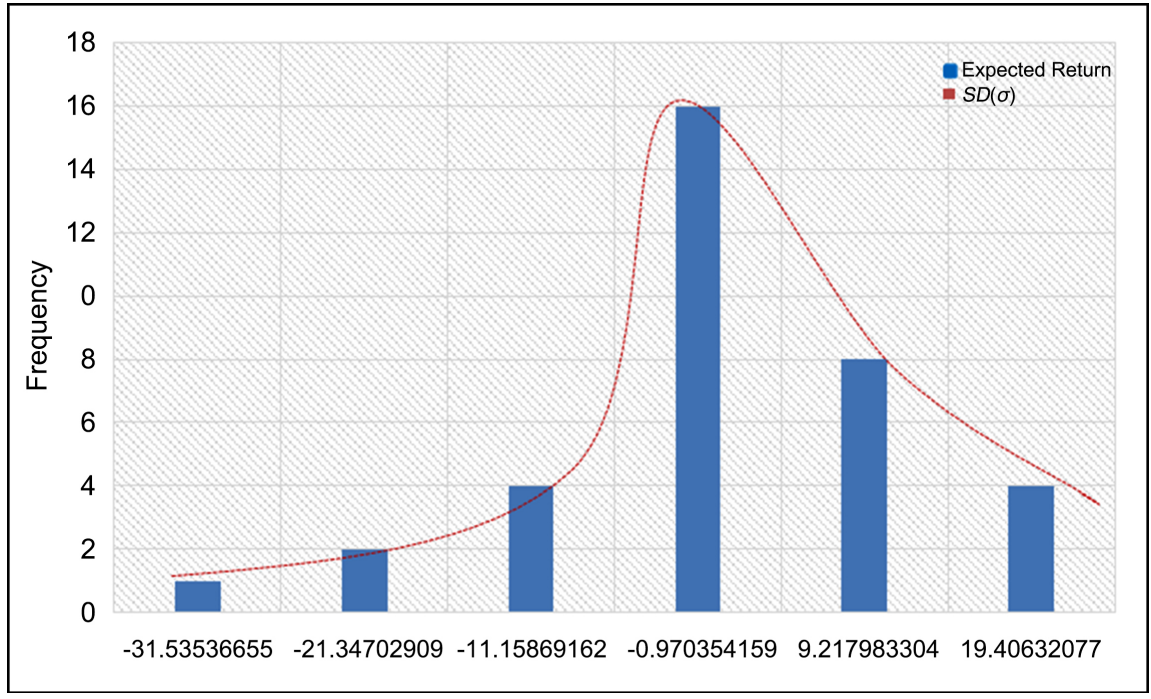

Figure 3. GE standard deviation normal distribution.

Some investors have so much confidence in the events, market views and opinions regarding a stock price which differ from the historical performance of GE that show not all investors are rational thinking, but some of their decisions are influenced by their emotions and level of understanding.

\section{Conclusion and Recommendation}

The Capital Pricing Asset Model theory assumptions had been widely criticized for many reasons, through empirical testing by using the General Electric's performance; it is unrealistic and only applicable in a perfect market as it does not consider the factors that are affecting GE. However, the theory could be used to have a general look at systematic risk (Beta). Furthermore, GE had gone through 
many fluctuations during 2017 and 2020 and it is still struggling presently as the coronavirus had impacted its industrial free cash flow which resulted in a large drop in its stock price in February and March of 2020.

CAPM uses past data as contributions to explain for a future return of an asset. But the past may not be enough to use for forecasting the future and CAPM methods have used betas that depend on future risk estimates. Other critiques of CAPM are that in the risk measure, non-varying beta is used, which is contrary to the views of most economist and analysist such as Jordan (2016) that risk is of a varying nature (non-constant). The model assumes that there are no taxes or transaction costs, although this assumption may be relaxed with more complicated versions of the model.

However, since the research is conducted in the Kingdom of Saudi Arabia, there is limitation of gathering primary facts and data collection. The research methodology is highly restricted to the data collection and analysis from trusted secondary resources through the internet the other limitation is the time constraints.

\section{Conflicts of Interest}

The authors declare no conflicts of interest regarding the publication of this paper.

\section{References}

Ball, R. (1978). Anomalies in Relationships between Securities' Yields and Yield-Surrogates. Journal of Financial Economics, 6, 103-126. https://doi.org/10.1016/0304-405X(78)90026-0

Baker, M., Brendan, B., \& Jeffrey, W. (2010). Benchmarks as Limits to Arbitrage: Understanding the Low-Volatility Anomaly. Financial Analysts Journal, 67, 40-54.

https://doi.org/10.2469/faj.v67.n1.4

Black, F., Scholes, M., \& Jensen, M. (1972). The Capital Asset Pricing Model: Some Empirical Tests. In M. C. Jensen (Ed.), Studies in the Theory of Capital Markets. New York: Praeger.

Blitz, D., Vliet, V., \& Guido, B. (2019). The Volatility Effect Revisited. Journal of Portfolio Management, 46. https://doi.org/10.3905/jpm.2019.1.114

Blitz, D., Falkenstein, E., \& Vliet, P. (2014). Explanations for the Volatility Effect: An Overview Based on the CAPM Assumptions. The Journal of Portfolio Management, 40, 61-76. https://doi.org/10.3905/jpm.2014.40.3.061

Banz, R. W. (1981). The Relationship between Return and Market Value of Common Stocks. Journal of Financial Economics, 9, 3-18. https://doi.org/10.1016/0304-405X(81)90018-0

Basu, S. (1983). The Relationship between Earnings Yield, Market Value, and Return for NYSE Common Stocks: Further Evidence. Journal of Financial Economics, 12, 129-156. https://doi.org/10.1016/0304-405X(83)90031-4

Cheng, P. L., \& Graver, R. (1980). An Alternative Test of the Capital Asset Pricing Model. American Economic Review, 70, 660-671.

Fama, E., \& French, K. (2004). The Capital Asset Pricing Model: Theory and Evidence. 
Journal of Economic Perspectives, 18, 25-26. https://doi.org/10.1257/0895330042162430

General Electric Company Financial Reports (2017). Retrieved on December 31st from United States Securities and Exchange Commission.

Gibbons, M. (1980). Econometric Methods for Testing a Class of Financial Models-An Application of the Nonlinear Multivariate Regression Model. PhD Dissertation, Chicago, IL: University of Chicago.

Hansen, S. (2020). The Rise and Fall of General Electric (GE). Investopedia. https://www.investopedia.com/insights/rise-and-fall-ge

Harindra, S. (2012). Exploiting the Volatility Anomaly in Financial Markets. CFA Institute Conference Proceedings Quarterly, 29, 47-56. https://doi.org/10.2469/cp.v29.n1.2

Kenton, W. (2019). Capital Asset Pricing Model (CAPM). Investopedia. https://www.investopedia.com/terms/c/capm.asp

Lintner, J. (1965a). The Valuation of Risk Assets and the Selection of Risky Investments in Stock Portfolios and Capital Budgets. Review of Economics and Statistics, 47, 13-37. https://doi.org/10.2307/1924119

Lintner, J. (1965b). Security Prices, Risk and Maximal Gains from Diversification. Journal of Finance, 20, 587-615. https://doi.org/10.1111/j.1540-6261.1965.tb02930.x

Lee, M. C., \& Su, L. E. (2014). Capital Market Line Based on Efficient Frontier of Portfolio with Borrowing and Lending Rate. Journal of Accounting and Finance, 2, 69-76.

Markowitz, H. (1952). Portfolio Selection. Journal of Finance, 7, 77-91. https://doi.org/10.1111/j.1540-6261.1952.tb01525.x

Markowitz, H. (1959). Portfolio Selection: Efficient Diversifications of Investments. Cowles Foundation Monograph, No. 16, New York: John Wiley \& Sons, Inc.

Markowitz, H. M. (1999). The Early History of Portfolio Theory: 1600-1960. Financial Analysts Journal, 55, 5-16. https://doi.org/10.2469/faj.v55.n4.2281

Marsh, T. (1980). Intertemporal Capital Asset Pricing and the Term Structure of Interest Rates. PhD Dissertation, Chicago, IL: Graduate School of Business, University of Chicago.

Mossin, J. (1966). Equilibrium in a Capital Asset Market. Econometrica, 35, 768-783. https://doi.org/10.2307/1910098

Owens, J. C. (2018). General Electric Booted from Dow Jones Industrial Average. MarketWatch.

https://www.marketwatch.com/story/general-electric-booted-from-dow-jones-industri al-average-2018-06-19

Reinganum, M. R. (1981). Misspecification of Capital Asset Pricing: Empirical Anomalies Based on Earnings Yields and Market Values. Journal of Financial Economics, 9, 19-46. https://doi.org/10.1016/0304-405X(81)90019-2

Sharpe, W. F. (1964). Capital Asset Prices: A Theory of Market Equilibrium under Conditions of Risk. Journal of Finance, 19, 425-442. https://doi.org/10.1111/j.1540-6261.1964.tb02865.x

Siegel, R. (2019). General Electric Issues Expanded Response about Fraud Allegations, Financial Reporting. The Washington Post. https://www.washingtonpost.com/business/2019/08/19/general-electric-issues-expande d-response-about-fraud-allegations-financial-reporting

Tlemsani, I., \& Nuaimi, A. (2018). Islamic versus Conventional Banks Performance during the Financial Crisis: Application to the UAE. International Journal of Accounting 
and Financial Reporting, 8, 221-240. https://doi.org/10.5296/ijafr.v8i1.12822

Treynor, J. L. (1962). Toward a Theory of Market Value of Risky Assets. In R. A. Korajczyk (Ed.), Asset Pricing and Portfolio Performance (1999) (pp. 15-22). Unpublished Manuscript, Final Version, London: Risk Books. 